\title{
Mutual Coupling Reduction of DRA for MIMO Applications
}

\author{
Noha Al Shalaby ${ }^{1}$, Shamia El-Sherbiny ${ }^{1}$ \\ ${ }^{1}$ Electrical engineering Dept., Faculty of Engineering, Kafr el sheikh University, Kafr el sheikh- Egypt ${ }^{1}$, \\ *corresponding author, E-mail: noha1511ahm@yahoo.com
}

\begin{abstract}
In this paper, A Multiple Input Multiple Output (MIMO) antenna using two Square Dielectric Resonators Antennas (SDRAs) is introduced. The mutual coupling between the two SDRAs is reduced using two different methods; the first method is based on splitting a spiral slot in the ground plane, then filling the slot with dielectric material, $\varepsilon_{r}=2.2$. The second method is based on inserting a copper parasitic element, having the same shape of the splitted spiral, between the two SDRAs. The effect of replacing the copper parasitic element with carbon nanotubes (CNTs) parasitic element is also studied. The antenna system is designed to operate at 6 GHz. The analysis and simulations are carried out using finite element method (FEM). The defected ground plane method gives a maximum isolation of $18 \mathrm{~dB}$ at element spacing of 30 $\mathrm{mm}\left(0.6 \lambda_{\mathrm{o}}\right)$, whereas the parasitic element method gives a maximum isolation of $48.5 \mathrm{~dB}$ at the same element spacing.
\end{abstract}

\section{Introduction}

MIMO, an abbreviation to multiple input multiple output, refers to a technology based on sending and receiving more than one data signal simultaneously with the aim to increase the channel capacity and hence, increasing the data rates that can be transmitted over the channel. MIMO can be achieved through employing multiple antennas at the transmitter and receiver. One problem with this technique is the coupling between adjacent antennas which affects the system performance. Therefore, reducing the mutual coupling is considered as an important objective during the design of MIMO system [1].

Antenna, as an important part of wireless communication system, has gained a lot of attention and development. Recently, Dielectric Resonator Antenna, DRA, is massively researched as a candidate for conventional antenna types. DRA offers many advantages such as ease of fabrication, small size, wide bandwidth and high radiation efficiency [28]. Mutual coupling problem has been treated in literature for both microstrip antenna and dielectric resonator antenna [9-17].

A group of researchers studied the mutual coupling of a cylindrical dielectric resonator antenna, CDRA, and that of circular microstrip antenna, the results of this work showed that CDRA has an advantage of better isolation compared to circular microstrip antenna [9]. Several techniques are used to reduce the mutual coupling between DRAs. In [10], an artificial magnetic conductor in place on the ground plane is used. In [11], mutual coupling is reduced by defecting the ground plane. In [12], the radiation characteristics of a single element DRA on the cylindrical ground plane are investigated. The mutual coupling is reduced by introducing slots in the cylindrical ground plane. The mutual coupling reduction is achieved by using an air gap between the dielectric resonator antenna and the ground plane in [13].

It is noticed from literature that most of the methods used for mutual coupling reduction are based on defecting the ground plane, DG, either for single band or multiband arrays, and this is reasonably based on the fact that the main cause of mutual coupling is the surface wave. Defected ground plane is achieved through etching some parts from it, which in turn disturbs the current distribution and hence reduce the surface waves effect. The shape of the etched part from the ground can control the mutual coupling reduction level. Some researchers modelled the DG as a resonant circuit having a rejection band related to the shape of the slots introduced to the ground as in [14-17].

Through this work, a MIMO system based on two square DRAs is designed, the mutual coupling between SDRAs is investigated and reduced by two different techniques; the first one is based on defecting the ground through splitting a spiral part of it, whereas the second technique is based on using a parasitic spiral shape between the two SDRAs. The effect of the parasitic element material on the mutual coupling coefficient is investigated. The proposed design provides a compact MIMO antenna with higher isolation.

\section{Simulations and Numerical results}

Through this section, a square dielectric resonator antenna, SDRA, is designed and then the performance of the two elements SDRAs array is investigated. Finally, the problem of the mutual coupling between the array elements is treated. Two different methods are introduced to make the array design suitable for MIMO antenna system. 


\subsection{Square Dielectric Resonator Antenna (SDRA) Structure.}

The SDRA is designed to operate at $6 \mathrm{GHz}$. Figure 1 shows the geometry and the dimensions of the with side length $b=13$ $\mathrm{mm}$, and dielectric constant $\varepsilon_{r}=5.7$. It is mounted on a square perfect conductor ground plane with side length $l_{g}=70 \mathrm{~mm}$. A coaxial probe with a radius of $r_{p}=0.2 \mathrm{~mm}$ is used to excite the element. The probe is located off the centre by $d_{f}=2.67$ $\mathrm{mm}$ with a height $h_{p}$ of $6.5 \mathrm{~mm}$. Figure 2 represents the simulated reflection coefficient as a function of frequency. SDRA has a resonance frequency of $6 \mathrm{GHz}$ and bandwidth of 200MHz. The simulated results are calculated by using the FEM [18, 19] and compared with that calculated by FIT method [20]. Good agreement is obtained between the two calculated results.

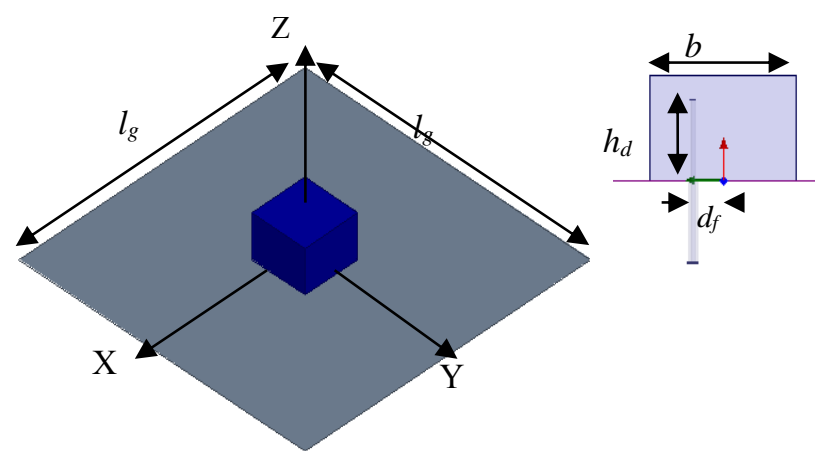

Figure 1: The structure of square DRA element.

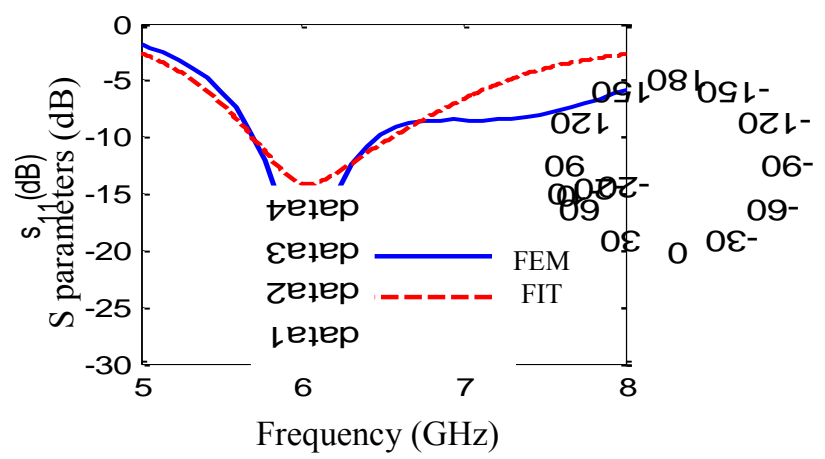

Figure 2: Reflection coefficient versus frequency for the SDRA.

\subsection{Two SDRAs Array Structure.}

The mutual coupling between the array elements should be taken into account because of its effect on the array performance, including resonance frequency, bandwidth and radiation patterns. Through this part, the performance of the two SDRAs is investigated before introducing the mutual coupling reduction techniques. Figure 3 represents the structure of a two-element MIMO array, which is formed from the previously designed square DR antenna with element-spacing $d=30.8 \mathrm{~mm}\left(0.6 \lambda_{\mathrm{o}}\right)$.

Figure 4 represents the reflection coefficient, $S_{11}\left(\left|S_{11}\right|=\right.$ $\left.\left|S_{22}\right|\right)$ of the array and the mutual coupling, $S_{21} \cdot\left(I S_{12} \mid=\right.$ $\left.\left|S_{21}\right|\right)$ between the array elements versus frequency. The array has a resonance frequency of $6.5 \mathrm{GHz}$, bandwidth of 1 $\mathrm{GHz}$ and isolation of $-17.5 \mathrm{~dB}$ at $6.5 \mathrm{GHz}$. E-plane and
H-plane radiation patterns of SDRA array at $6.5 \mathrm{GHz}$ are depicted in Figure 5. Good agreement between the results is obtained by using FEM and that of FIT.

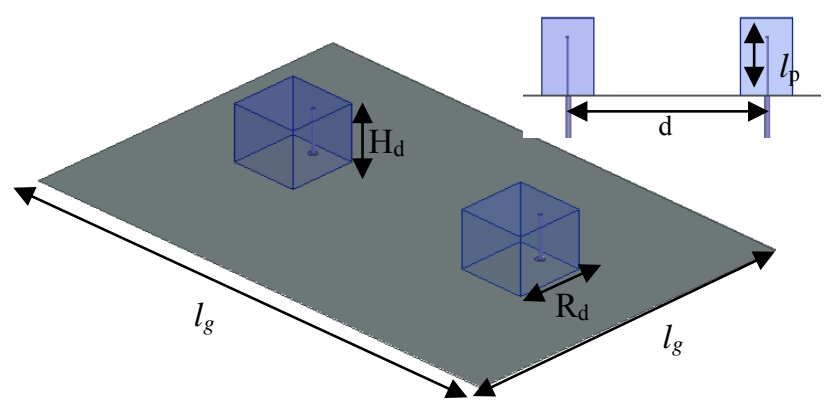

Figure 3: Geometry of the two elements of SDRA antenna array.

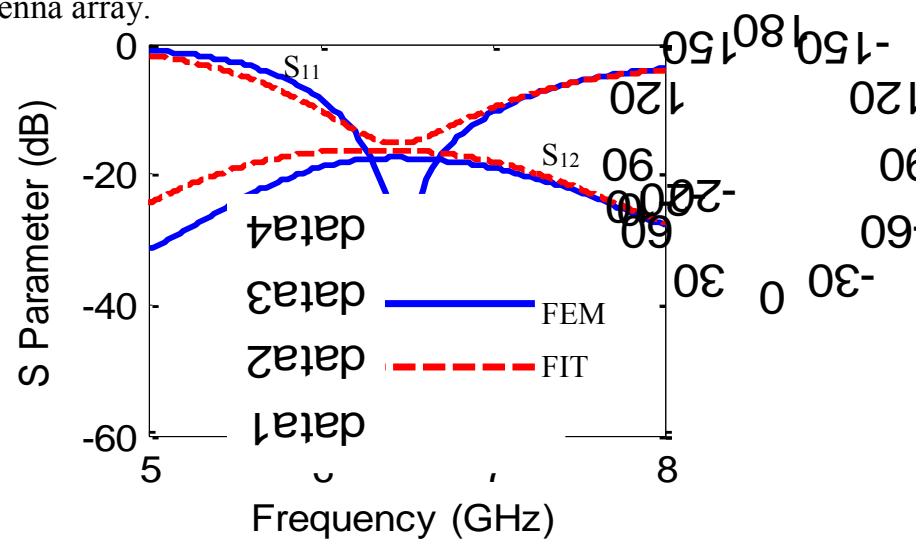

Figure 4: S-parameter sjegddation of SDRA

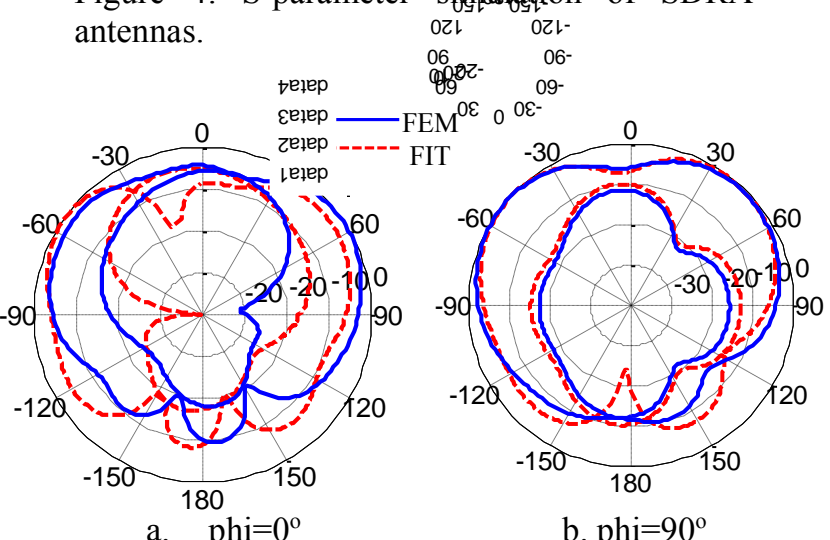

a. $\mathrm{phi}=0^{\circ}$

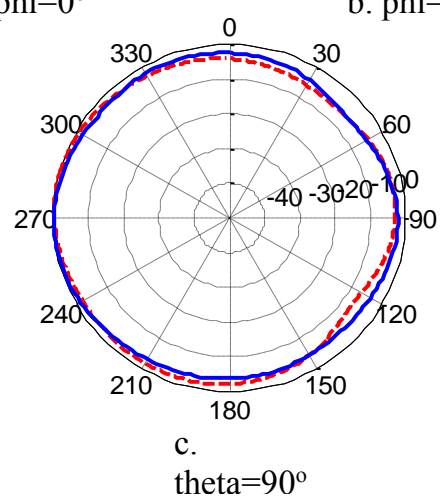

Figure 5: Radiation pattern of two SDRA at frequency $6.5 \mathrm{GHz}$. 


\subsection{The first design for Mutual coupling reduction between the two SDRAs.}

structure (DGS). DGS can be considered as an alternative form of electromagnetic band gap structure, EBG, and hence can be used to suppress the surface waves which are the main cause of mutual coupling. The effect of DGS can be concluded in the disturbance in current distribution which in turn results in additional inductance, capacitance and resistance that form RLC circuit which acts as a band reject filter at certain frequencies. The characteristics of the filter can be controlled by the shape and the dimensions of the slots. The DGS in this paper is composed of splitting a spiral slot in the ground plane. The dimensions of the slot are designed to give stop-band around $6.5 \mathrm{GHz}$, as shown in Fig. 6. $a=20.6 \mathrm{~mm}, b=16 \mathrm{~mm}, a_{I}=13 \mathrm{~mm}, b_{I}=6.5$ $\mathrm{mm}, s=0.95 \mathrm{~mm}$. The calculated Sparameter, mutual coupling coefficient $S_{21}$ and the reflection coefficient $S_{11}$ between the two identical SDRAs versus frequency for one cell is shown in Fig. 7. The defected ground plane provides an improvement of isolation about $18.4 \mathrm{~dB}$ at $6.62 \mathrm{GHz}$.
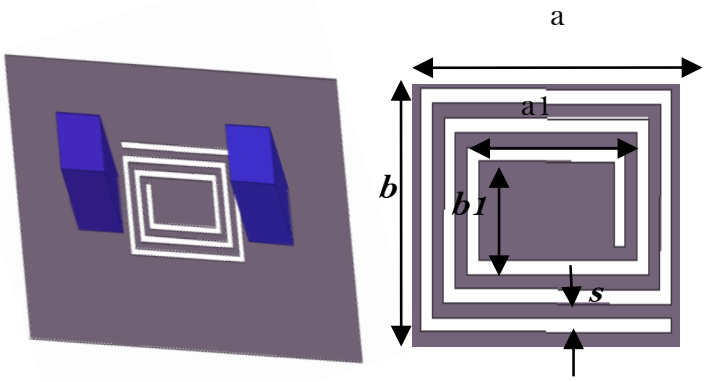

Figure 6: The two elements of the SDRA antenna array with DGS.

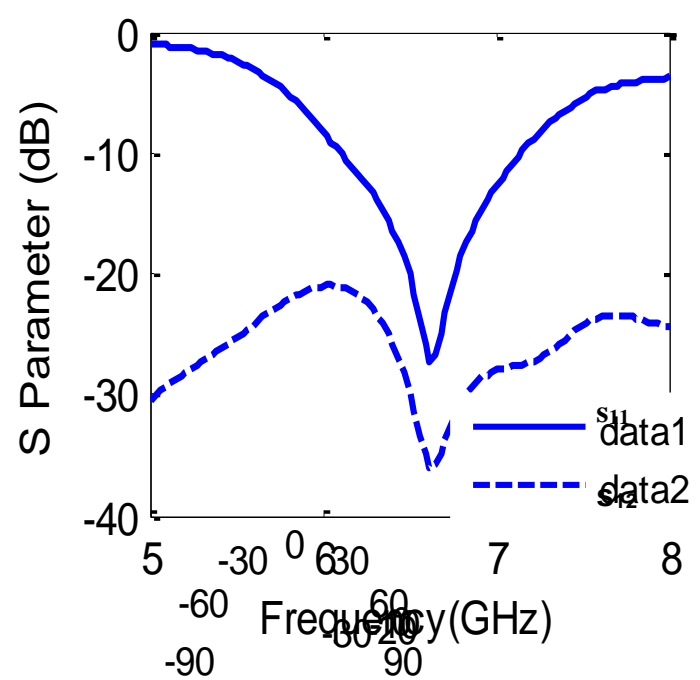

Figure 7: S-pparameter simulation result of SDRA antenna array with DGS 150

Figure.8 represents the radiation patterns in different planes for DGS at $6.62 \mathrm{GHz}$, a very little variation in radiation pattern. By filling the slot with dielectric material, $\varepsilon_{r l}=2.2$, the isolation about $17.5 \mathrm{~dB}$ at $6.6 \mathrm{GHz}$.
The S-parameter, $S_{11}$ and $S_{21}$ between the two identical SDRAs versus frequency are shown in Fig. 9. The effect of changing the dielectric material as, $\varepsilon_{22}=5.7$, and $\varepsilon_{B 3}$ $=10.2$, was studied. The best result is obtained at the value of $\varepsilon_{r l}=2.2$, and by increasing the value of $\varepsilon_{22}$ the isolation is reduced by14 $\mathrm{dB}$ at $6.62 \mathrm{GHz}$ for $\varepsilon_{r 2}$ and $10.5 \mathrm{~dB}$ for $\varepsilon_{B^{3}}$

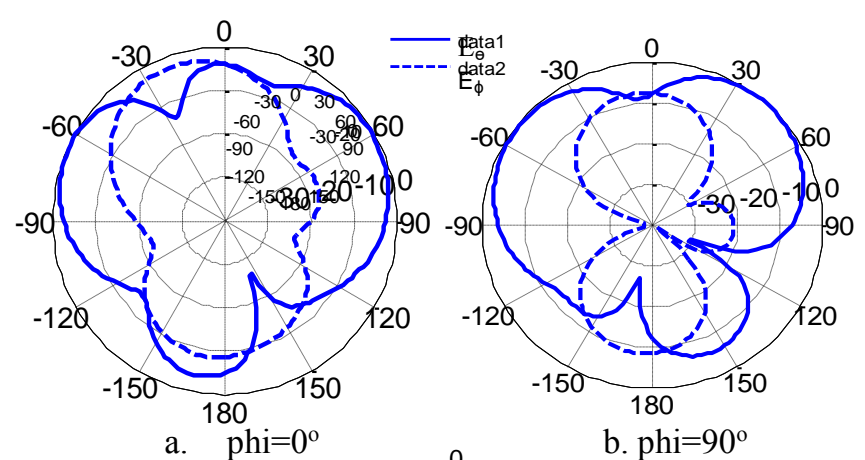

a. $\quad \mathrm{phi}=0^{\circ}$

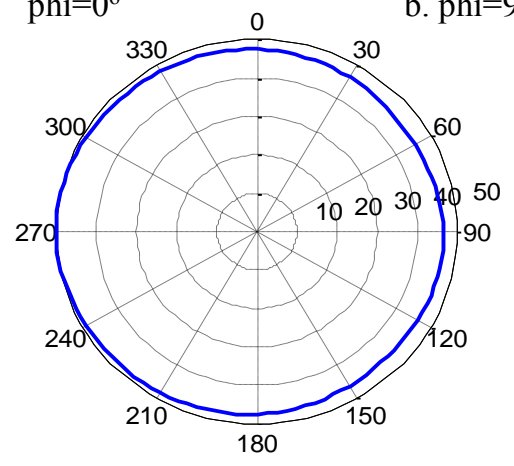

c. theta $=90^{\circ}$

Figure 8: Radiation pattern of two SDRA antennas at frequency $6.62 \mathrm{GHz}$.

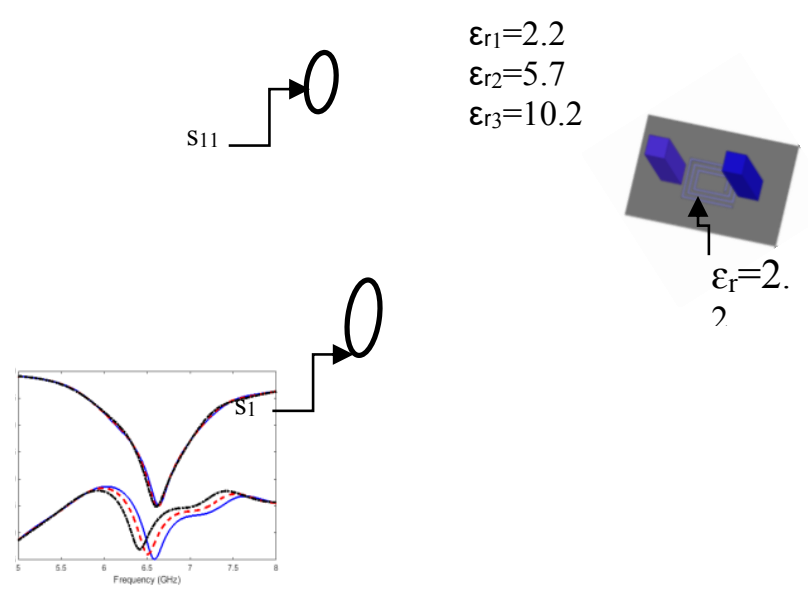

Figure 9: S-parameter simulation result of SDRA antenna array with DGS filling with dielectricresonator material. 


\subsection{The Second Design for Mutual Coupling Reduction between the Two SDRAs.}

In this part, mutual coupling reduction between two SDRA antennas is achieved by using copper parasitic elements having a rectangular spiral shape with dimensions, $w_{1}=9.5$ $\mathrm{mm}, w_{2}=3.9 \mathrm{~mm}, f_{l}=8.95 \mathrm{~mm}, f_{2}=4.75 \mathrm{~mm}, t=25 \mu \mathrm{m}$, as shown in Fig. 10. In this case, the rectangular spiral resonator acts as a band rejection filter and hence isolates the two antenna elements from each other. The equivalent circuit for spiral resonator is shown in Fig. 10-c, and the equivalent parameters (spiral inductance, $L_{S R}$, spiral capacitance, $C_{S R}$ and spiral resistance, $R_{S R}$ ) are calculated by using the following equations $[21,22]$.

$L^{S R}=\frac{\mu_{o}}{2 \pi} l_{\text {avg }}^{S R}\left[\ln \left(\frac{l_{\text {avg }}^{S R}}{2 t}\right)+\frac{1}{2}\right]$

$C^{S R}=\frac{l}{4(t+s)} \frac{N^{2}}{N^{2}+1} \times\left[w_{1}(N-1)-\frac{N^{2}-1}{2}(t+s)\right] C_{o}$

$l_{\text {avg }}=l_{\text {avg }}^{S R}=4 w_{1}-\left[2(N+1)-\frac{3}{N}\right](s+t)$

where $N$ is the number of turns of the spiral, $w_{l}$ is the side length of external length, $t$ is the width of strips, $s$ is the separation between adjacent turns. $C_{o}$ is defined as for the multiple strip ring resonator, and $l_{\text {avg }}$ is the average length of the spiral.

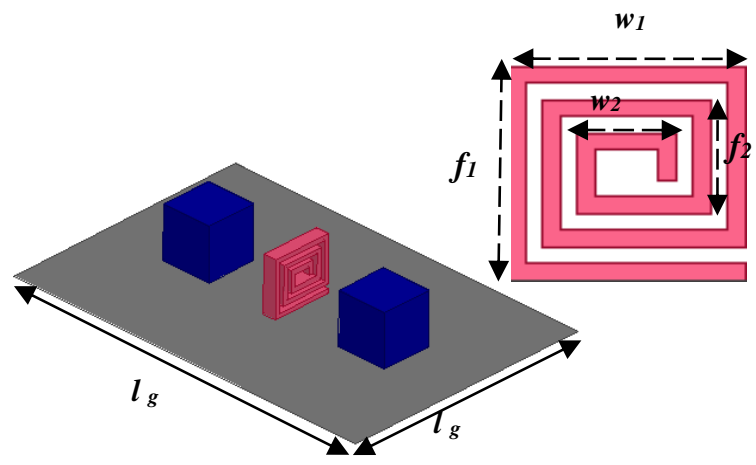

a. 3-D view.
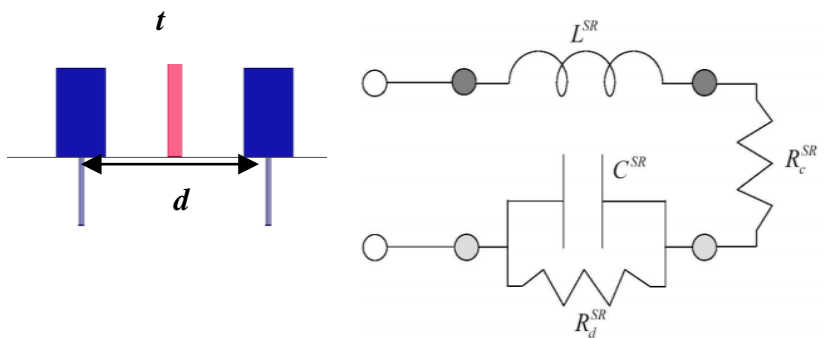

b. Side view. c. Equivalent circuit of spiral resonator.

Figure 10: The two element of SDRA antennas array with copper parasitic element and its equivalent circuit.

The calculated $S$-parameter, mutual coupling coefficient $\mathrm{S}_{21}$ and the reflection coefficient $S_{11}$ between the two identical SDRAs versus frequency for copper parasitic element, at $t=25 \mu \mathrm{m}$, are shown in Fig. 11. The inserting copper parasitic element between the two SDRAs provides an improvement of isolation to about $17.5 \mathrm{~dB}$ at $6.56 \mathrm{GHz}$. Figure 12 shows the radiation patterns in different planes at $6.56 \mathrm{GHz}$. The effect of changing the thickness of the parasitic element $t$, was studied. At $t=25 \mu \mathrm{m}$, an improvement in the isolation to $17.5 \mathrm{~dB}$ at $6.56 \mathrm{GHz}$, is occur, at $t=0.6 \mathrm{~mm}$ the isolation is $18.5 \mathrm{~dB}$ at $6.44 \mathrm{GHz}$, and at $t=1.12 \mathrm{~mm}$ the is $18 \mathrm{~dB}$ at $6.44 \mathrm{GHz}$. There is a slight change in the isolation due to the thickness changing.
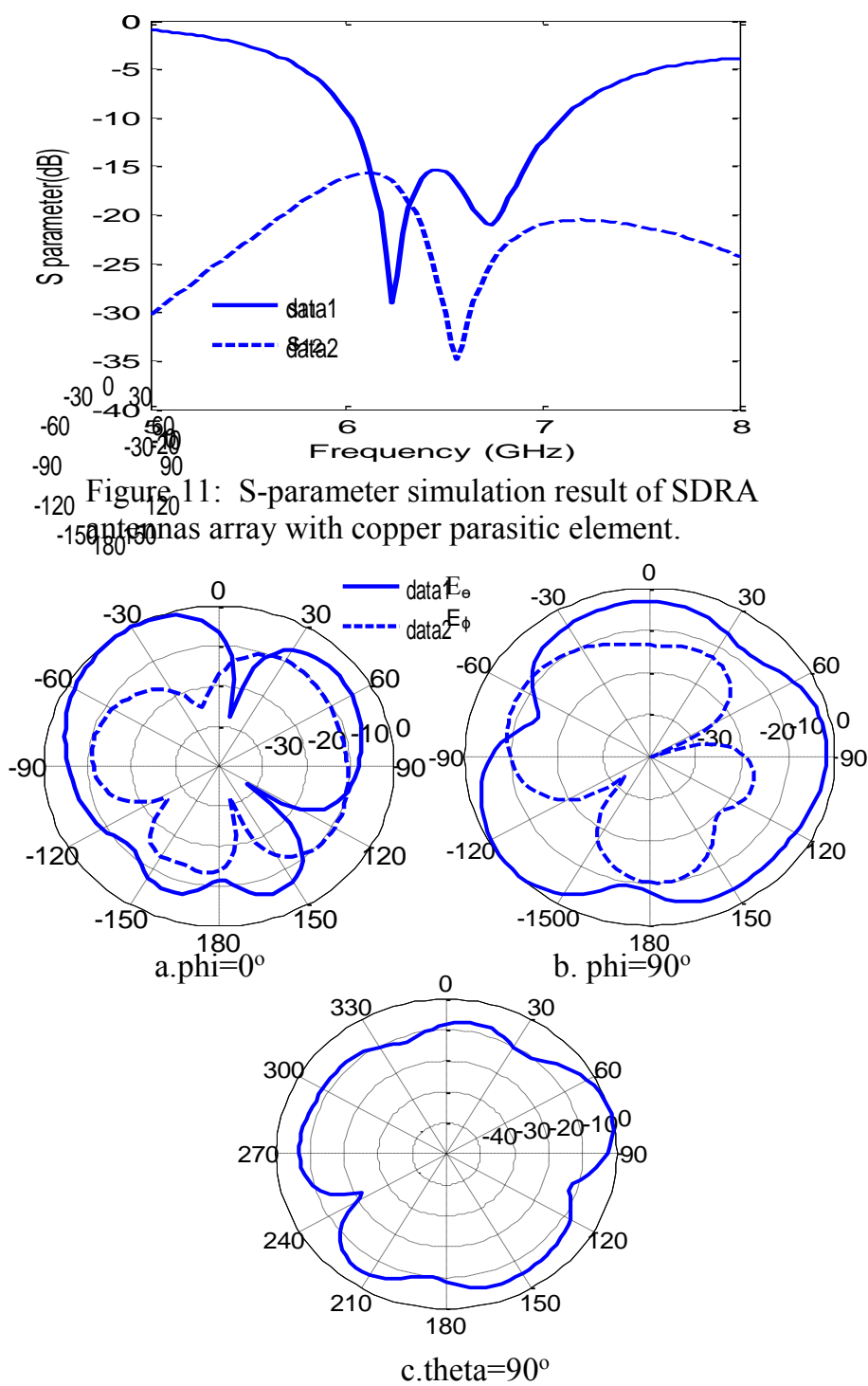

Figure 12: Radiation pattern of two SDRA antennas at frequency $6.56 \mathrm{GHz}$.

Finally, the copper parasitic element is replaced with Carbon nanotubes (CNTs) parasitic element "SOC12 doped long-MWCNT BP" with conductivity $6000 \mathrm{~S} \mathrm{~cm}^{-1}$ at $t=25 \mu \mathrm{m}$ [23]. The calculated $\mathrm{S}$ parameters, versus frequency are shown in Fig. 13. The simulated results indicate that using CNTs based-material as a parasitic element provides an improvement of isolation about 29 $\mathrm{dB}$ at $6.5 \mathrm{GHz}$. Fig. 14 shows the radiation patterns in different planes at $6.5 \mathrm{GHz}$. 


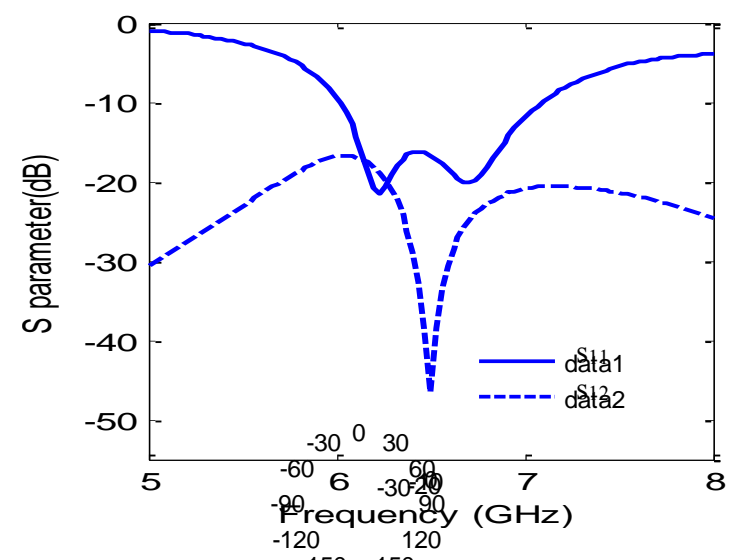

Figure 13: S-paffeqqtefer simulation result of SDRA antenna array with Bucky parasitic element.

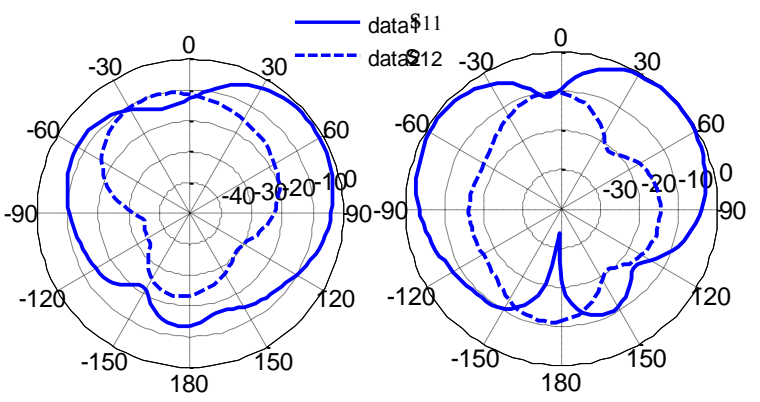

a.ph $=0^{\circ}$

b. $\mathrm{ph}=90^{\circ}$

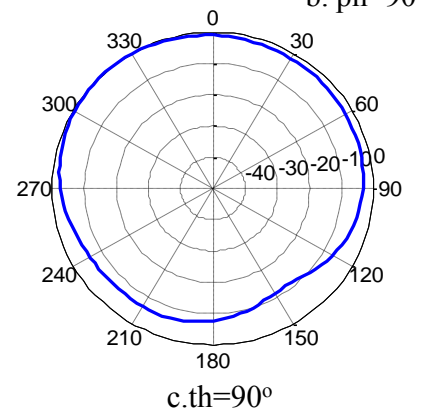

Figure 14: Radiation pattern of two SDRA antennas

In case better improvement in isolation level is achieved due to the additional kinetic inductors and quantum capacitors that characterize the CNTs which in turn affects the frequency response [23]. Using CNT based materials results in a very little variation in the radiation patterns.

Finally, the results of our proposed structures are compared with some results found in the literature. Table1. Summarizes the results of the previous researchers as well as our results. The comparison ensures the effectiveness of our proposed design which presents a compact MIMO antenna system with high interelement isolation that is desired for practical applications.
Table 1: Summary of some previous research results as well as our results

\begin{tabular}{|c|c|c|}
\hline reference & Structure & Isolation \\
\hline$[24]$ & $\begin{array}{l}\text { (patristic)/ } \\
\text { mushroom wall } \\
\text { structure }\end{array}$ & $42 \mathrm{~dB}$ \\
\hline$[25]$ & $\begin{array}{l}\text { (parasitic)/ an } \\
\text { array of split-ring } \\
\text { resonator unit- } \\
\text { cells }\end{array}$ & $\begin{array}{c}30 \text { to } 47 \\
\mathrm{~dB}\end{array}$ \\
\hline$[26]$ & $\begin{array}{l}\text { (parasitic) } \\
\text { /Rectangular } \\
\text { parasitic tape }\end{array}$ & $37.2 \mathrm{~dB}$ \\
\hline [27] & H shaped DGS & $10 \mathrm{~dB}$ \\
\hline [28] & $\begin{array}{l}\text { Concentrated } \\
\text { circular split ring } \\
\text { resonator DGS }\end{array}$ & $\begin{array}{c}27 \text { to } 33 \\
\text { dB }\end{array}$ \\
\hline \multicolumn{3}{|l|}{ Our results } \\
\hline $1^{\text {st }}$ structure & $\begin{array}{l}\text { copper parasitic } \\
\text { element }\end{array}$ & $35 \mathrm{~dB}$ \\
\hline $2^{\text {nd }}$ & DGS is composed & $37 \mathrm{~dB}$ \\
\hline structure & $\begin{array}{l}\text { of splitting a } \\
\text { spiral slot }\end{array}$ & \\
\hline $3^{\text {rd }}$ structure & $\begin{array}{l}\text { CNTs parasitic } \\
\text { element }\end{array}$ & $48 \mathrm{~dB}$ \\
\hline
\end{tabular}

\section{Conclusions}

In this paper design and simulation of two SDRA for MIMO applications are presented. The mutual coupling reduction is achieved exploiting two different methods; the first method based on defecting the ground plane through etching a spiral shape in the ground and the second one based on inserting a resonant parasitic element between the two elements of MIMO array. The DG method resulted in an isolation of $18.4 \mathrm{~dB}$, where the parasitic element method resulted in an isolation of $17.5 \mathrm{~dB}$ in case of copper and 29.5 $\mathrm{dB}$ in case of CNTs based-material. The impact of the two different methods of the SDRA characteristics is studied in each case.

\section{References}

[1] A.-H. Majeed, A.-S. Abdullah, R.-A. AbdAlhameed, K.-H. Sayidmarie, MIMO Antenna Array Using Cylindrical Dielectric Resonator for Wide Band Communications Applications, Int. J. Electromagnetics and Applications 4(2): 40-48, 2014.

[2] A. Sharma and S. C. Shrivastava, Bandwidth Enhancement Techniques of Dielectric Resonator Antenna, Int.J. Engineering Science and Technology 3: 5995-5999, 2011.

[3] M. I. Sulaiman, and S. IC. Khamas, A Singly Fed Rectangular Dielectric Resonator Antenna with A 
Wideband Circular, IEEE Antennas Wirel. Propag. Lett. 9: 615-618, 2010 .

[4] K. I. C. Gebril, S. K. A. Rahim, and A. Y. Abdurrahman, Bandwidth Enhancement and Miniaturization of Dielectric Resonator Antenna for 5.8GHz WLAN, Prog. Electromagn. Res. C 19: 179-189, 2011.

[5] A. H. Majeed, A. S. Abdullah, F. Elmegri, K. H. Sayidmarie, R. A. Abd-Alhameed and J. M. Noras., Aperture-Coupled Asymmetric Dielectric Resonators Antenna for Wideband Applications, IEEE Antennas Wirel. Propag. Lett. 13: 927-930, 2014.

[6] M. S.M. Aras, M. K. A Rahim, Z. Rasin and M. Z. A. Abdul Aziz., An Array of Dielectric Resonator Antenna for Wireless Application, Proc. IEEE International RF and Microwave Conference, Kuala Lumpur, Malysia, pp. 459-463, 2008.

[7] M. Brar and S. K. Shanna, A Wideband ApertureCoupled Pentagon Shape Dielectric Resonator Antenna (DRA) for Wireless Communication Applications, IEEE International Symposium on Antennas \& Propagation, pp.1674-1677, 2011.

[8] A. Sharma, K. Khare, S. C. Shrivastava., Dielectric Resonator Antenna for X Band Microwave Application, Int. J. Advanced Research in Electrical, Electronics and Instrumentation Engineering 2, (6): 2247-2252, 2013.

[9] R. Chair, A. A. Kishk and K. F. Lee., Comparative Study on the Mutual Coupling Between different sized cylindrical dielectric resonators antennas and Circular Microstrip Patch Antennas, IEEE Trans. Antennas Propag. 53 (3): 1011 - 1019, 2005.

[9] G. Zheng, A. A. Kishk, A.W. Glisson and A. B. Yakovlev, A mutual coupling reduction technique for dielectric resonator antennas over AMC surface, IEEE Antennas and Propagation Society Int. Symp., Albuquerque, NM, USA, pp. 377-380, 2006.

[10] D. Guha, S. Biswas, T. Joseph and M. T. Sebastian, Defected ground structure to reduce mutual coupling between cylindrical dielectric resonator antennas, Electron. Lett. 44(14): 836-837, 2008.

[11] S. H. Zainud-Deen, H. A. Malhat, and K.H. Awadalla, Dielectric Resonator Antenna Mounted on A Circular Cylindrical Ground Plane, Prog. Electromagn. Res. B 19: 427-444, 2010.

[12] R. Kumari, S. K. Behera, Mutual Coupling $\mathrm{Reduction}$ in $\mathrm{C}$-shaped Dielectric Resonator Antenna array for MIMO Applications, Poc. INDICON, Annual IEEE, India, 2012.

[13] F. Y. Zulkifli, E.T. R.ahardjo, and D. Hartanto, Mutual Coupling Reduction Using Defected Ground
Structure for Multiband Microstrip Antenna Array, Prog. Electromagn. Res. Lett. 13: 29-40, 2010.

[14] M. Kumar, V. Nath, Analysis of low mutual coupling compact multi-band microstrip patch antenna and its array using defected ground structure, Int. J. Engineering Science and Technology 19: 866-874, 2016.

[15] M. K. Khandelwal, B. K. Kanaujia, and S. Kumar. Defected Ground Structure: Fundamentals, Analysis, and Applications in Modern Wireless Trends, Int. J. Antennas and Propagation Article ID 2018527, 2017.

[16] Ch. Luo, J. Hong, M. Amin, Mutual Coupling Reduction for Dual-Band MIMO Antenna with Simple S1 ructure, Radio Engineering 26(1): 51-56, 2017.

[17] M. Karimi, A. Emadeddin, A. Darvazehban, A Novel Enhanced Mutual Coupling Reduction in Patch Antenna, Int. J. Scientific \& Engineering Research 8(3): 869-872, 2017.

[18] P. Solin, Partial Differential Equations and the Finite Element Method, John Wiley \& Sons, Inc., USA, 2006.

[19] Noha A, Saber H., Dielectric Resonator Antennas on Curved Surfaces, LAP Lambert Academic Publishing, 2013.

[20] R. Marklein. The finite integration technique as a general tool to compute acoustic, electromagnetic, elastodynamic, and coupled wave fields, IEEE Press. pp. 201-44, 2002.

[21] K. Buell, H. Mosallaei, and K. Sarabandi, A substrate for small patch antennas providing tunable miniaturization factors, IEEE Trans. Microw. Theory Tech. 54(1): 135-146, 2006.

[22] F. Bilotti, A. Toscano, L. Vegni, K. Aydin, K. B. Alici, and E. Ozbay, Equivalent-Circuit Models for the Design of Metamaterials Based on Artificial Magnetic Inclusions, IEEE Trans. Microw. Theory Tech. 55(12): 2865-2873, 2007

[23] J. Park, J. Louis, Q. Cheng, J. Bao, J. Smithyman, R. Liang, B. Wang, Ch. Zhang, J. S. Brooks, L. Kramer, P. Fanchasis and D. Dorough, Electromagnetic interference shielding properties of carbon nanotube buckypaper, Nanotechnol. 20(41), 415702, 2009.

[24] G. Zhai, Z.N. Chen, and X.Qing, Enhanced Isolation of a Closely Spaced Four-Element MIMO Antenna System using Metamaterial Mushroom, IEEE Trans. Antennas Propag. 63(8), 3362-3370, 2015.

[25] A. Dadgarpour, B. Zarghooni, B. S. Virdee,T. A. Denidni and A. A. Kishk, Mutual Coupling Reduction in Dielectric Resonator Antennas Using Metasurface Shield for $60 \mathrm{GHz}$ MIMO Systems, IEEE Antennas Wirel. Propag. Lett. 16: 477-480,2016.

[26] S. Neogi, A. K. Bhattacharjee, P. P. Sarkar, Size reduction of rectangular microstrip antenna, Microw. Opt. Technol. Lett. 56(1): 244-248, 2014. 
[27] Y. Zhang, B. Niu , Compact Ultra wide Band (UWB) slot antenna with wideband and high isolation for MIMO applications, Prog. Electromagn. Res. C 59: 9-16, 2014.

[28] L. Liu, S. W. Cheung, T. Yuk, Compact MIMO antenna for portable UWB applications with band-notched characteristic, IEEE Trans. Antennas Propag. 63(5): 19171924, 2015. 